\title{
Perforating palmar disease in TTR-related familial amyloid polyneuropathy
}

\author{
Mal perfurante palmar na polineuropatia amiloidótica familiar ligada à TTR
}

Paulo Victor Sgobbi de Souza', Thiago Bortholin', Carlos Alberto Castro Teixeira', Daniel Delgado Seneor', Vitor Dias Gomes Barrios Marin', Fernando George Monteiro Naylor'1, Wladimir Bocca Vieira de Rezende Pinto', Acary Souza Bulle Oliveira ${ }^{1}$

A60-year-old retired woman presented with upper and lower limb paresthesias since age 40 and chronic diarrhea and weakness. She worked as a teacher. Her deceased mother had experienced similar symptoms. Neurological examination disclosed dysautonomic features (Figure 1), severe sensory loss of vibration and proprioceptive senses and a moderate decrease of pain and temperature sensation with stocking-glove distribution, and perforating palmar disease (Figure 2). Neurophysiological studies disclosed severe axonal sensorimotor polyneuropathy.
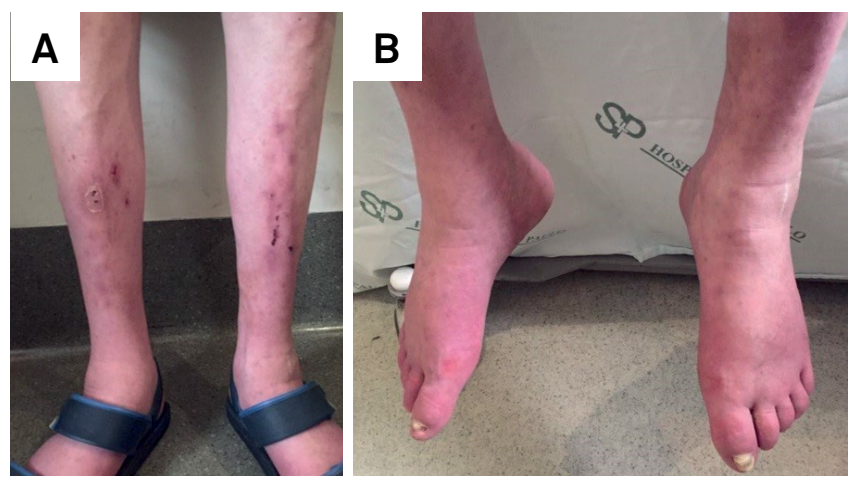

Figure 1. Dysautonomic and sensory and motor findings in TTRrelated familial amyloid polyneuropathy. Clinical examination showing skin color changes, mild edema (A), and bilateral foot drop (B), which initiated a neuropathic steppage gait. Plantar surfaces of both feet were spared from ulcerations.
Laboratory tests were unremarkable. The pathogenic heterozygous variant Val50Met in the TTR gene defined TTR-related familial amyloid polyneuropathy ${ }^{1}$. This finding highlights perforating palmar disease as a rare complication of familial amyloid polyneuropathy ${ }^{2,3}$. Neurogenic perforating palmar ulcers may occur in neuropathies due to: (i) severe distal sensory loss and high risk of multiple local microtrauma; (ii) vasomotor disturbances to peripheral dysautonomia and sympathetic dysfunction with chronic hypoperfusion ${ }^{4}$.

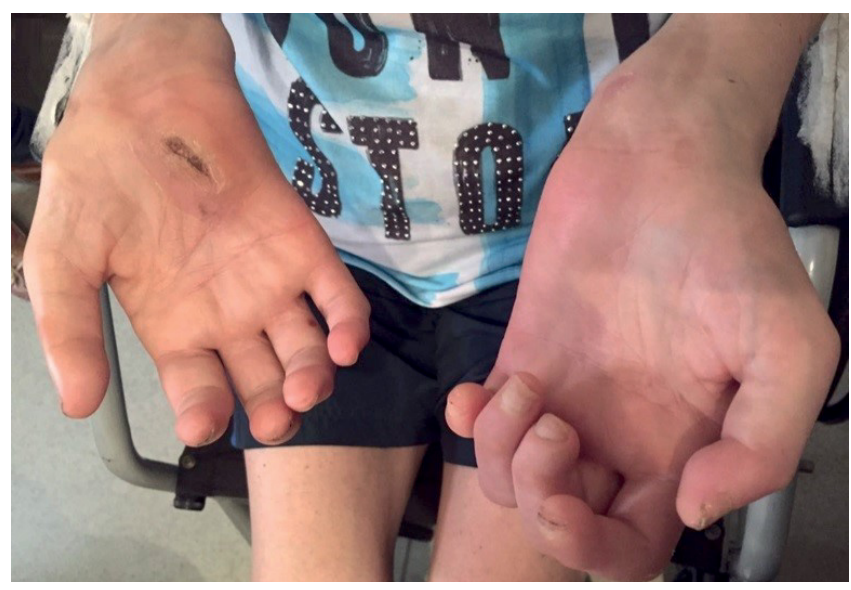

Figure 2. Perforating palmar disease and neuropathic ulceration in a patient with familial amyloid polyneuropathy. Examination showing the presence of neurogenic ulcer in the right hand, marked distal amyotrophy of thenar and hypothenar region of both hands, and skin color changes. Perforating palmar disease is more commonly associated with chronic sensory polyneuropathy, such as diabetes, leprosy and vasculitis ${ }^{1,2,3}$.

References

diagnosis. J Clin Neuromuscul Dis. 2009 Mar;10(3):126-34. https://doi.org/10.1097/CND.0b013e318196f0b2

3. Shin SC, Robinson-Papp. Amyloid neuropathies. Mt Sinai J Med. 2012 Nov;79(6):733-48. https://doi.org/10.1002/msj.21352

4. Araújo AQ, Barros Neto H, Bulcão H, Nascimento OJ. Trophic ulcers in the carpal tunnel syndrome. Arq Neuropsiquiatr. 1993 Sep;51(3):386-8. https://doi.org/10.1590/S0004-282X1993000300017

1 Universidade Federal de São Paulo, Departamento de Neurologia e Neurocirurgia, Divisão de Doenças Neuromusculares, São Paulo SP, Brasil;

Correspondence: Paulo Victor Sgobbi de Souza; Departamento de Neurologia e Neurocirurgia da UNIFESP; Rua Estado de Israel, 899 ; $04022-002$ São Paulo SP, Brasil; E-mail:pvsgobbi@gmail.com

Conflict of interests: There is no conflict of interest to declare.

Received 03 January 2018; Received in final form 09 April 2018; Accepted 11 April 2018. 